\title{
Phrenic nerve conduction studies: normative data and technical aspects
}

\author{
Aspectos técnicos e normatização da neurocondução do nervo frênico \\ Analucia Abreu Maranhão', Sonia Regina da Silva Carvalho', Marcelo Ribeiro Caetano², \\ Alexandre Hofke Alamy ${ }^{3}$, Eduardo Mesquita Peixoto 4 , Pedro Del Esporte Peçanha Filgueiras ${ }^{5}$
}

\begin{abstract}
Objective: The aim of the present study was to define normative data of phrenic nerve conduction parameters of a healthy population. Methods: Phrenic nerve conduction studies were performed in 27 healthy volunteers. Results: The normative limits for expiratory phrenic nerve compound muscle action potential were: amplitude (0.47 mv - $0.83 \mathrm{mv})$, latency ( $5.74 \mathrm{~ms}-7.10 \mathrm{~ms})$, area (6.20 ms/mv - $7.20 \mathrm{~ms} / \mathrm{mv})$ and duration (18.30 ms - $20.96 \mathrm{~ms}$ ). Inspiratory normative limits were: amplitude (0.67 mv - $1.11 \mathrm{mv})$, latency (5.90 ms - $6.34 \mathrm{~ms})$, area (5.62 ms/mv - $6.72 \mathrm{~ms} / \mathrm{mv}$ ) and duration (13.77 ms - $15.37 \mathrm{~ms}$ ). Conclusion: The best point of phrenic nerve stimulus in the neck varies among individuals between the medial and lateral border of the clavicular head of the sternocleidomastoid muscle and stimulation of both sites, then choosing the best phrenic nerve response, seems to be the appropriate procedure.
\end{abstract}

Keywords: electrodiagnosis; reference values; phrenic nerve; spirometry; neural conduction.

\section{RESUMO}

Objetivo: O objetivo do presente estudo foi definir os dados normativos de condução do nervo frênico de uma população saudável. Métodos: Foram realizados estudos de condução do nervo frênico em 27 voluntários saudáveis. Resultados: Os limites normais do potencial de ação muscular composto do nervo frênico durante a expiração foram: amplitude (0.47 mv - 0.83 mv), latência (5.74 ms - 7.10 ms), área (6.20 ms/mv - 7.20 ms/mv) e duração (18.30 ms - 20.96 ms). E durante a inspiração os limites normais foram: amplitude (0.67 mv - 1.11 mv), latência (5.90 ms - $6.34 \mathrm{~ms})$, área ( $5.62 \mathrm{~ms} / \mathrm{mv}$ - $6.72 \mathrm{~ms} / \mathrm{mv}$ ) e duração (13.77 ms - $15.37 \mathrm{~ms})$. Conclusão: 0 melhor ponto de estímulo do nervo frênico no pescoço varia entre a borda medial e lateral da cabeça clavicular do músculo esternocleidomastóideo. Estimular ambos os locais e escolher a melhor resposta do nervo frênico parece ser o procedimento mais adequado.

Palavras-chave: eletrodiagnóstico; valores de referência; nervo frênico; espirometria; condução nervosa.

Phrenic nerve conduction has found increasing application in the diagnosis of respiratory dysfunction associated with surgical, neuromuscular, and pulmonary disorders ${ }^{1,2,3,4,5,6}$, which are important causes of respiratory failure and frequently contribute to difficulties in weaning patients off the ventilator in the critical care unit ${ }^{7}$. To determine a neuromuscular cause of hypercapnic respiratory failure, respiratory electrodiagnostic studies are often used $^{8}$.

Recently, many authors have correlated phrenic nerve conduction abnormalities with chronic obstructive pulmonary disease. These studies demonstrated abnormal phrenic compound motor action potential (CMAP) amplitudes and latencies in chronic obstructive pulmonary disease patients ${ }^{9,10,1,12}$.
Innervated by the phrenic nerve, the diaphragm is the principal respiratory muscle in humans. The diaphragmatic CMAPs are recorded with chest surface electrodes following phrenic nerve stimulation in the neck. Amplitude, latency, and area are measures used to evaluate phrenic nerve integrity $1,2,3,4,5,6,7,13$.

The amplitude measure of the CMAP is commonly used to define neuropathy of the phrenic nerve and is an important parameter in patient selection for pacing the diaphragm. However, the range of the amplitude among healthy individuals is very wide, making it difficult to establish a real cutoff limit. Therefore, it would be very helpful if we had a parameter, like the spirometry test, that correlates with the CMAP.

'Universidade Federal do Estado do Rio de Janeiro, Faculdade de Medicina, Departamento de Pneumologia, Rio de Janeiro RJ, Brasil; ${ }^{2}$ Universidade Federal do Estado do Rio de Janeiro, Faculdade de Medicina, Departamento de Neurocirurgia, Rio de Janeiro RJ, Brasil; ${ }^{3}$ Private Practice, Rio de Janeiro, Rio de Janeiro, Brazil;

4 Universidade Federal do Estado do Rio de Janeiro, Faculdade de Enfermagem, Rio de Janeiro RJ, Brasil;

${ }^{5}$ Universidade Federal do Estado de Rio de Janeiro, Faculdade de Medicina, Rio de Janeiro RJ, Brasil.

Correspondence: Analucia A Maranhão; Rua Maris e Barros, 775; 20270-001 Rio de Janeiro RJ, Brasil; E-mail: aamaranhao66@gmail.com

Conflict of interest: There is no conflict of interest to declare.

Received 05 June 2017; Received in final form 26 July 2017; Accepted 21 August 2017. 
There are several approaches to stimulate the phrenic nerve in the neck, but a stimulation in the supraclavicular fossa, just above the clavicles, is considered to obtain the best results ${ }^{14}$. Therefore, it remained to be determined if the best point to stimulate is between the two heads of the sternocleidomastoid muscle or lateral to the clavicular head of this muscle.

The aims of the present study were to define normative data of phrenic nerve neuroconduction parameters of a Brazilian healthy population, and discuss some of the technical aspects of the procedure.

\section{METHODS}

The study group consisted of 27 volunteers (15 men), 21-62 years old (median, 30 years), with no respiratory or neuromuscular disorders, all of whom had normal spirometry tests and chest X-rays. The participants' data were as follows: height, 155-186 cm (mean, $171 \mathrm{~cm}$ ); and weight, 52-100/ kg (mean, $73 \mathrm{~kg}$ ). The study recruited students and employees (with different degrees of physical activity) from the university hospital. The study was approved by the Gaffrée Guinle University Hospital Ethics Committee, and all participants provided informed consent.

The spirometry test procedure used the forced vital capacity (FVC) technique in which the participant performs a full inspiration and then a forceful expiration, as rapidly and completely as possible. Each participant performed, in the sitting position, at least three trials and the best performance was used for analysis. An adequate test required a minimum of three acceptable FVC maneuvers. The test was considered acceptable when the difference between the largest and the next largest FVC and the first second of forced expiratory volume $\left(\mathrm{FEV}_{1}\right)$ was $0.150 \mathrm{~L}$ or less $^{15}$. The prediction equations of Knudson ${ }^{16}$ were used for the Time-Volume and Flow-Volume curves. Parameters analyzed were: FVC, FEV 1 and the $\mathrm{FEV}_{1} / \mathrm{FVC}$ ratio. A Spiron (Physis, Rio de Janeiro, Brazil) spirometer was used.
Postero-anterior and lateral chest X-ray films were obtained at maximal inspiration. The radiographs were acquired by a trained radiographer and were read by the chest physician.

Phrenic neuroconduction was performed with participants lying in a supine position, with a bipolar stimulating electrode (Neurosoft, Ivanovo, Russia) between the sternal and clavicular heads of the sternocleidomastoid muscle, just above the clavicle as described by Resman-Gaspersc and Podnar ${ }^{14}$; however, in almost one third of participants, we had to stimulate lateral to the clavicular head, as described by Chen et al. ${ }^{7}$, to get a better CMAP. We used two disposable self-adhesive disk recording electrodes (Viasys Healthcare, Madison, Wisconsin). The active electrode (G1) was fixed $5 \mathrm{~cm}$ above the xiphoid process, and the reference electrode (G2) $16 \mathrm{~cm}$ from G1, on the chest margin ipsilateral to the stimulated phrenic nerve. An electromyography system (NEURO-Mep-Micro, Neurosoft, Ivanovo, Russia) with standard settings ( filters: $2 \mathrm{~Hz}$ to $10 \mathrm{kHz}$ ) was used. The gain was set to $0.5 \mathrm{mv}$ and the sweep speed to $2 \mathrm{~ms} /$ division. Bilateral studies were performed on all participants. Electrical stimulation was carried out with rectangular pulses of $0.1 \mathrm{~ms}$ or $0.2 \mathrm{~ms}$ duration. Measurements were made separately during normal inspiration and expiration (Figure 1). Phrenic nerve CMAP onset latency (ms), amplitude (mV), duration (ms), and area of the negative phase were obtained at supramaximal stimulation (10\%-20\% above maximal stimulation).

The measurements from 27 healthy nonsmoking volunteers were organized and analyzed in a Microsoft Excel spreadsheet. The analysis was done by $\mathrm{R}$, freeware statistical analytics software. All participants had body mass index values under normality limits. The distribution of the numeric variables was tested using the Shapiro-Wilk normality test at $5 \%$ significance levels. The variables: age, $\mathrm{FEV}_{1} \%$ and $\mathrm{FVC} \%$ did not have normal distribution, so they were analyzed using a nonparametric approach. All other variables, considered normally distributed

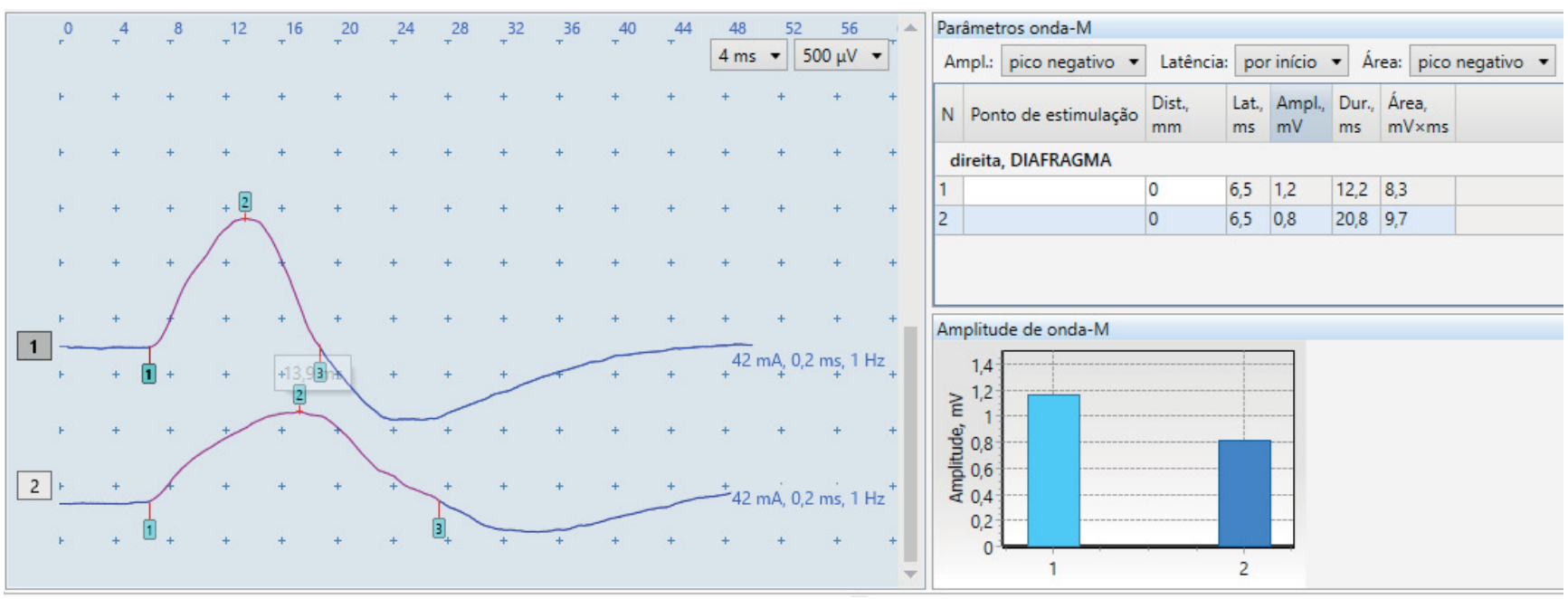

Inspiratory CMAP is sharper and higher-reduced duration and increased amplitude comparing to expiratory CMAP (compound muscle action potential).

Figure 1. Phrenic inspiratory and expiratory CMAPs. 
by the test, were analyzed with a parametric approach at $95 \%$ confidence intervals. No significance was found between the left and right side regarding the measurements made relating to the phrenic nerve, using the paired $t$-test. Therefore, the average values obtained from both sides were calculated for each participant, and common normative data were obtained. Categorization for inferential analysis: Gender: male and female; Height: 1.55-1.72m, 1.73-1.86m; Weight: 52-75.99kg, 76-100kg; Age: under 30 years, 30 years or more.

\section{RESULTS}

The summary of neuroconduction parameters, the profile of the 27 participants studied and the spirometric parameters are shown in Table 1. The CMAP amplitudes, latencies, duration, and areas, as $\mathrm{FEV}_{1}, \mathrm{FVC}$ and $\mathrm{VEF}_{1} / \mathrm{CVF}$ had normal limits defined according to the confidence interval at $95 \%$. Expiratory CMAP normative limits were: amplitude $(0.47$ $\mathrm{mv}-0.83 \mathrm{mv})$, latency $(5.74 \mathrm{~ms}-7.10 \mathrm{~ms})$, area $(6.20 \mathrm{~ms} / \mathrm{mv}-7.20$ $\mathrm{ms} / \mathrm{mv}$ ) and duration $(18.30 \mathrm{~ms}-20.96 \mathrm{~ms})$. Inspiratory CMAP normative limits were: amplitude $(0.67 \mathrm{mv}-1.11 \mathrm{mv})$, latency (5.90 ms-6.34 ms), area (5.62 ms/mv-6.72 ms/mv) and duration $(13.77 \mathrm{~ms}-15.37 \mathrm{~ms})$. Lower and upper limits of spirometric parameters: $\mathrm{FEV}_{1}(3.54 \mathrm{~L}-4.16 \mathrm{~L}), \mathrm{FVC}(4.26 \mathrm{~L}-5.12 \mathrm{~L})$ and $\mathrm{FEV}_{1} / \mathrm{FVC}$ (80.38-84.64). Age did not have a normal distribution and its median was 27 years, ranging from 21-62 years. The FEV ${ }_{1} \%$ and FVC\% did not have normal distributions either

and showed medians equal to 104.20 , ranging between 82.00 and 164.20 , and equal to 104.3 , ranging between 74.00 and 182.50, respectively.

The Pearson correlation is shown in Table 2 and strong correlations among the variables: $\mathrm{FEV}_{1}, \mathrm{FVC}$, height, inspiratory latency and weight are illustrated in Figure 2.

Table 2. Pearson correlation matrix represented as percentage for normal distribution variables: Height, spirometric parameters and neuroconduction parameters.

\begin{tabular}{|c|c|c|c|c|c|}
\hline Variable & BMI & $\mathrm{fev} / 01$ & FVC & Height & Weight \\
\hline Expiratory amplitude & $30.07 \%$ & $35.79 \%$ & $39.42 \%$ & $22.42 \%$ & $29.04 \%$ \\
\hline Expiratory area & $-21.52 \%$ & $-1.49 \%$ & $-2.00 \%$ & $0.02 \%$ & $-15.36 \%$ \\
\hline Expiratory duration & $-37.50 \%$ & $-14.94 \%$ & $-19.02 \%$ & $-25.72 \%$ & $-34.27 \%$ \\
\hline Expiratory latency & $43.40 \%$ & $56.47 \%$ & $58.98 \%$ & $42.56 \%$ & $47.83 \%$ \\
\hline $\mathrm{fev} / 01$ & $55.05 \%$ & $100 \%$ & $95.80 \%$ & $85.20 \%$ & $76.00 \%$ \\
\hline FVC & $54.08 \%$ & $95.80 \%$ & $100 \%$ & $81.94 \%$ & $73.68 \%$ \\
\hline Height & $65.26 \%$ & $85.20 \%$ & $81.94 \%$ & $100 \%$ & $88.24 \%$ \\
\hline Inspiratory amplitude & $28.47 \%$ & $34.65 \%$ & $38.42 \%$ & $23.40 \%$ & $27.97 \%$ \\
\hline Inspiratory area & $-10.73 \%$ & $6.62 \%$ & $8.15 \%$ & $13.37 \%$ & $-3.11 \%$ \\
\hline Inspiratory duration & $-19.69 \%$ & $-4.94 \%$ & $-2.86 \%$ & $-13.28 \%$ & $-16.13 \%$ \\
\hline Inspiratory latency & $50.88 \%$ & $77.66 \%$ & $76.00 \%$ & $79.88 \%$ & $69.49 \%$ \\
\hline $\begin{array}{l}\text { The values in bold ar } \\
\text { correlations were foun } \\
\text { or } \mathrm{FEV}_{1} \% \text {. Correlation } \\
\text { latency is shown. Ther } \\
\text { neuroelectrical param }\end{array}$ & & strong & ositive cor & rrelations. & $\begin{array}{l}\text { No strong } \\
\text { age, FVC\% } \\
\text { inspiratory }\end{array}$ \\
\hline
\end{tabular}

Table 1. Numerical summaries of phrenic nerve neuroconduction, spirometric and general parameters.

\begin{tabular}{|c|c|c|c|c|c|c|c|c|}
\hline Variable & Mean & SD & $50 \%$ & $5 \%$ & $95 \%$ & Min & Max & $95 \% \mathrm{Cl}$ \\
\hline Exp. Amplitude & 0.65 & 0.47 & 0.55 & 0.37 & 0.92 & 0.30 & 2.89 & $(0.47-0.83)$ \\
\hline Exp. Area & 6.70 & 1.33 & 6.75 & 4.98 & 8.53 & 3.00 & 9.15 & $(6.20-7.20)$ \\
\hline Exp. Duration & 19.63 & 3.52 & 18.95 & 15.16 & 26.42 & 14.20 & 26.80 & $(18.30-20.96)$ \\
\hline Exp. Latency & 6.42 & 1.79 & 6.10 & 5.32 & 7.07 & 5.25 & 14.90 & $(5.74-7.10)$ \\
\hline Insp. Amplitude & 0.89 & 0.59 & 0.80 & 0.50 & 1.22 & 0.50 & 3.65 & $(0.67-1.11)$ \\
\hline Insp. Area & 6.17 & 1.47 & 6.25 & 3.41 & 8.17 & 3.15 & 8.85 & $(5.62-6.72)$ \\
\hline Insp. Duration & 14.57 & 2.12 & 14.00 & 11.55 & 17.81 & 11.30 & 19.10 & $(13.77-15.37)$ \\
\hline Insp. Latency & 6.12 & 0.58 & 6.20 & 5.32 & 6.87 & 5.05 & 7.25 & $(5.90-6.34)$ \\
\hline Age & 30.74 & 10.5 & 27.00 & 23.00 & 52.70 & 21.00 & 62.00 & - \\
\hline Body mass index & 24.65 & 2.93 & 24.42 & 20.14 & 29.42 & 19.84 & 29.96 & $(23.55-25.75)$ \\
\hline Height & 1.72 & 0.09 & 1.71 & 1.56 & 1.85 & 1.55 & 1.86 & $(1.69-1.75)$ \\
\hline Weight & 73.33 & 14.6 & 75.00 & 53.00 & 97.40 & 52.00 & 100.00 & $(67.79-78.87)$ \\
\hline $\mathrm{fev} / 01$ & 3.85 & 0.82 & 3.86 & 2.76 & 5.17 & 2.67 & 5.19 & $(3.54-4.16)$ \\
\hline $\mathrm{FEV}_{1}, \mathrm{FVC}$ & 82.51 & 5.65 & 83.36 & 74.71 & 90.06 & 71.02 & 93.50 & $(80.38-84.64)$ \\
\hline $\mathrm{FEV}_{1} \%$ & 105.6 & 17.1 & 104.2 & 90.14 & 137.9 & 82.00 & 164.20 & - \\
\hline FVC & 4.69 & 1.13 & 4.38 & 3.25 & 6.67 & 3.05 & 6.72 & $(4.26-5.12)$ \\
\hline FVC\% & 106.5 & 22.6 & 104.3 & 81.1 & 150.0 & 74.0 & 182.5 & - \\
\hline
\end{tabular}

The summary of neuroconduction parameters, the profile of the 27 participants studied and the spirometric parameters are presented here. We also present general information such as age, height, weight and body mass index. The confidence interval was supressed for the variables considered as not normal distribution. Those using 5\% and 95\% measures are more representative. Exp: expiration; Insp: inspiration; FEV forced vital capacity; Min: minimum; Max: maximum. 


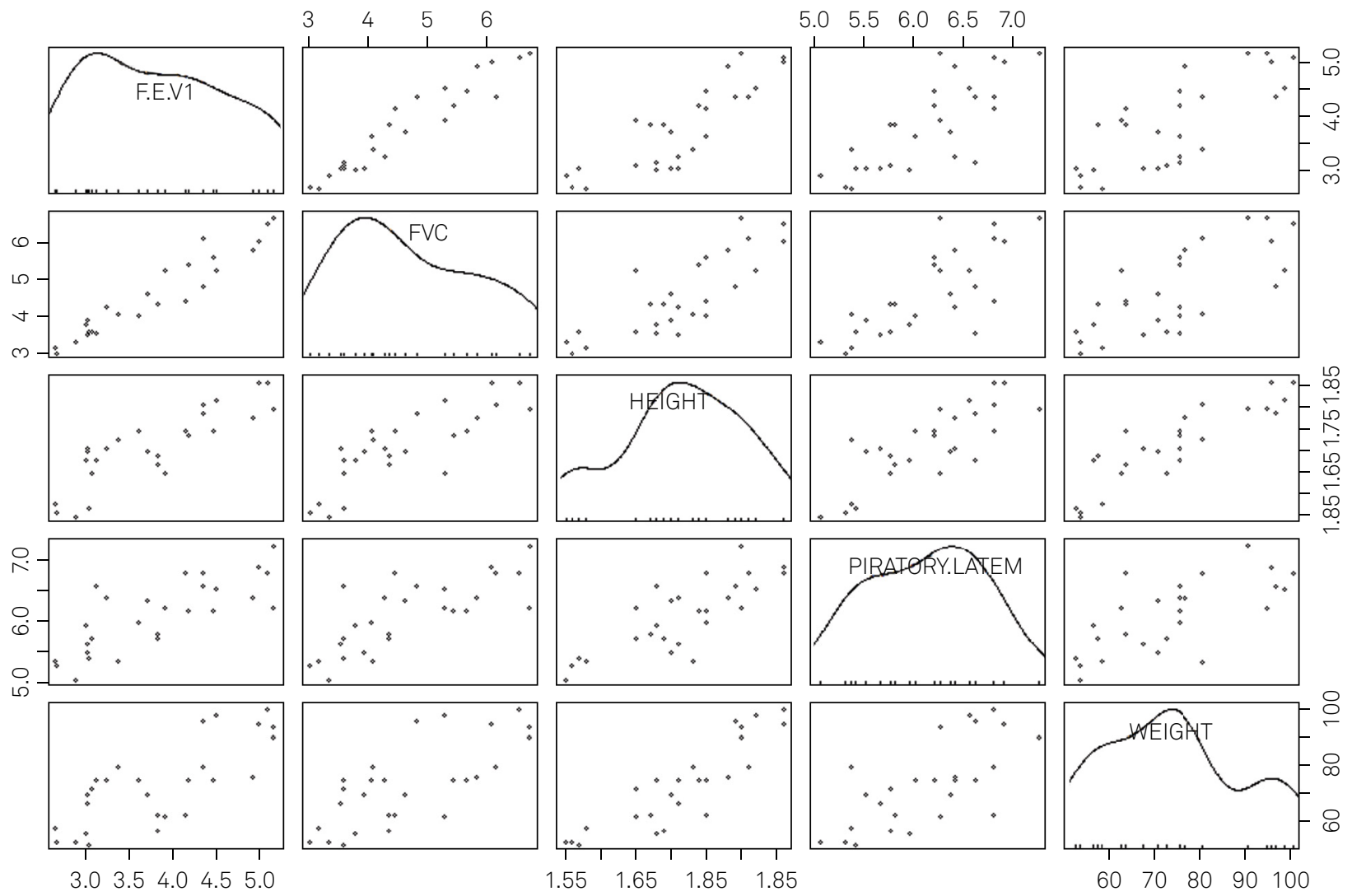

The strong correlations found in Table 2 among the variables: FEV, FVC, height, inspiratory latency and weight are illustrated here. As the correlation increases,

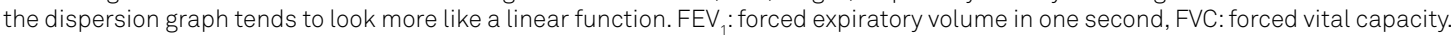

Figure 2. Dispersion diagram for strongly correlated variables.

Inferential analysis by categorization of gender, height, weight and age, disclosed statically significant differences between eight variables and borderline differences in six, by using the t-test for parametric variables and Wilcoxon test for nonparametric ones. The significant results can be seen in Table 3 and the categories in the study of gender and height are further analyzed below.

Gender Analysis (Figure 3):

1) Weight-Women were $20.85 \%$ (mean) lighter than men;

2) Inspiratory latency-Men had results $11.67 \%$ (mean) higher than women;

3) Height-Men were $6.6 \%$ (mean) taller than women;

4) Expiratory latency-Men were $18.02 \%$ (mean) higher than women;

5) Inspiratory duration-Women were $13.23 \%$ (mean) longer than men;

6) Age- Men were $17.24 \%$ (median) older than women;

7) Inspiratory amplitude- Men were $34.07 \%$ (mean) higher than women.

Height Analysis (Figure 4):

a) Inspiratory latency: was $10.49 \%$ (mean) higher in the taller group;

b) Expiratory latency: was $19.67 \%$ (mean) higher in the taller group.
Table 3. Inferential analysis: Hypothesis tests by categorization of gender, height, weight and age.

\begin{tabular}{lc}
\hline Variables & p-values \\
\hline Insp. latency by gender & 0.001 \\
Insp. latency by height & 0.001 \\
\hline Insp. latency by weight & 0.004 \\
Insp. duration by gender & 0.027 \\
FEV \% by age & 0.043 \\
Exp. latency by gender & 0.051 \\
Exp. latency by height & 0.055 \\
Exp. latency by weight & 0.055 \\
Insp. duration by age & 0.066 \\
FVC\% by age & 0.083 \\
Insp. amplitude by gender & 0.094 \\
\hline
\end{tabular}

The values in bold were obtained by the Wilcoxon test, while the other values were obtained by the $t$-test. The most significant relationships were related to inspiratory latency. The significance level adopted was $5 \%$ and the interval $5 \%-10 \%$ was considered borderline. The table only shows $p$-values $<0.10$, the other variables were tested but they were not significant enough. Exp: expiration; Insp: inspiration; FEV : forced expiratory volume in one second, FVC: forced vital capacity

\section{DISCUSSION}

Although the technique described by Resman-Gaspersc and Podnar ${ }^{14}$ was the best approach in the majority of the participants, in one third of them, stimulating the lateral 

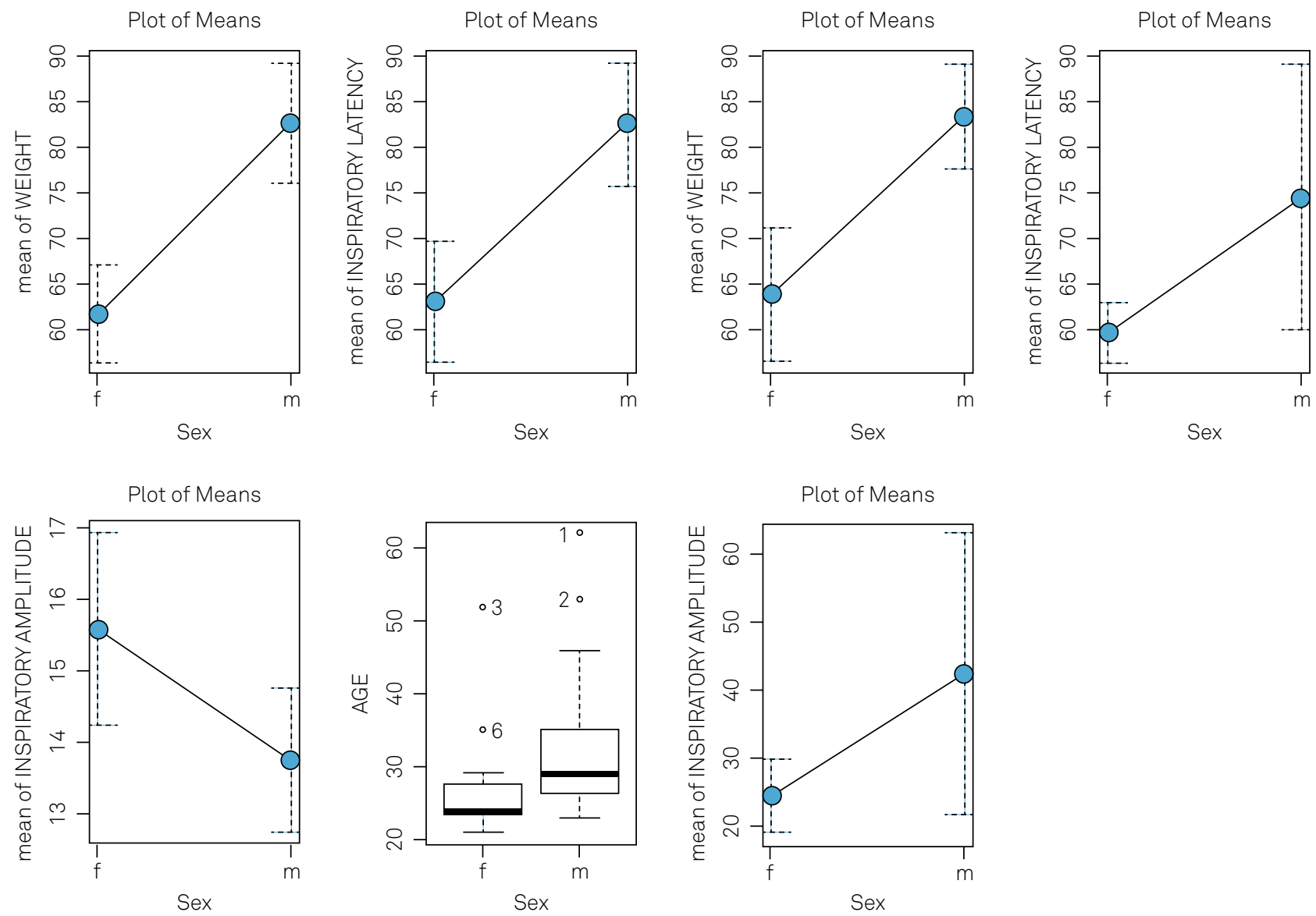

The mean of the variables with significant differences by gender are shown with a confidence interval at $95 \%$ for variables with normal distribution and boxplots for variables without normal distribution.

Figure 3. Graphic representation of the significant differences found by gender: general and neurophysiologic parameters.

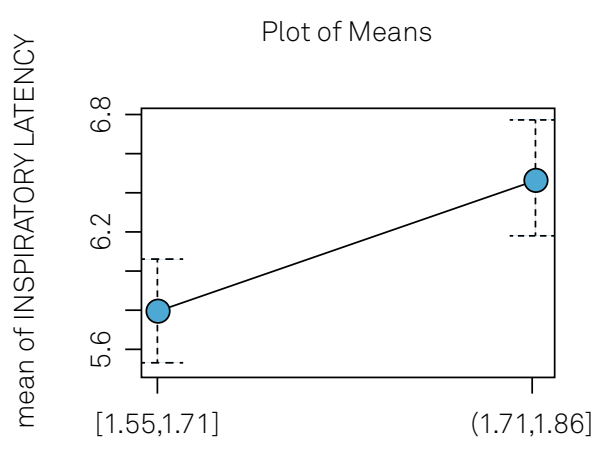

heightcat

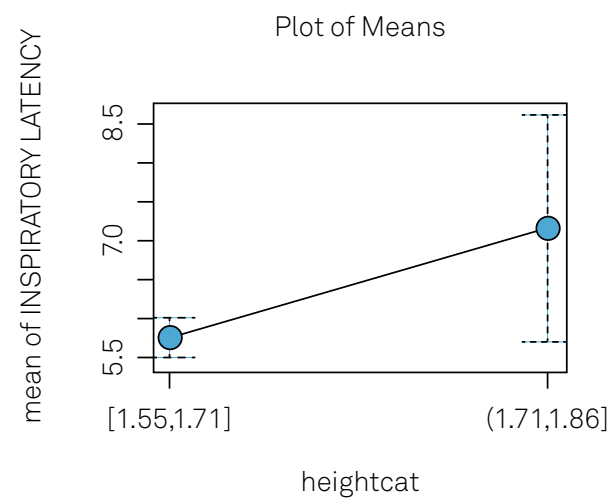

The mean of the variables with significant differences by height are showed with a confidence interval at $95 \%$ for variables with normal distribution and boxplots for variables without normal distribution. Lower height tends to result in lower latencies measurement both inspiratory and expiratory.

Figure 4. Graphic representation of the significant differences found by height categories: neurophysiologic parameters.

side of the clavicular head of the sternocleidomastoid muscle, as reported by Chen et al. ${ }^{7}$, showed reproducible CMAPs with higher amplitudes and reliable morphology. We could avoid inadvertent brachial plexus stimulation (detected by arm movement) by positioning the stimulator firmly in a more medial direction, which produces a "hiccup" sensation. We also had greater difficulty in stimulating the left side in some participants, as described by Resman-Gaspersc and Podnar ${ }^{14}$, probably due to anatomic differences.

The mean latency (inspiration $6.42 \mathrm{~ms}$, expiration $6.12 \mathrm{~ms}$ ) obtained was very close to that reported by Chen et al. ${ }^{7}$ (6.54 ms), Resman-Gaspersc and Podnar ${ }^{14}$ (inspiration $6.55 \mathrm{~ms}$, expiration $6.59 \mathrm{~ms}$ ) and that of Swenson and Rubenstein ${ }^{1}$ (right $6.28 \mathrm{~ms}$, left $6.30 \mathrm{~ms}$ ). The other reports by 
Newsom Davis ${ }^{2}$, MacLean and Mattioni ${ }^{3}$, Markland et al. ${ }^{4}$ and Mckenzie and Gandevia ${ }^{5}$ had a different stimulation site, at the level of the thyroid cartilage, which may explain the higher latencies (7.70 ms, $7.44 \mathrm{~ms}, 7.77 \mathrm{~ms}$, and $7.68 \mathrm{~ms}$, respectively).

The average amplitude we obtained (inspiration $0.78 \mathrm{mv}$, expiration $0.57 \mathrm{mv}$ ) was close to that obtained by Chen et al. ${ }^{7}$ (0.66 mv) and Markland et al. ${ }^{4}$ (right $0.79 \mathrm{mv}$, left $0.77 \mathrm{mv}$ ); lower than that obtained by Resman-Gaspersc and Podnar ${ }^{14}$ (inspiration $1.0 \mathrm{mv}$, expiration $0.71 \mathrm{mv}$ ); and higher than Swenson and Rubenstein $^{1}(0.35 \mathrm{mv})$. The wide range of the phrenic nerve amplitude creates a great problem in determining a lower normal limit. Swenson and Rubenstein ${ }^{1}$ found $0.10 \mathrm{mv}$, Chen et al. ${ }^{7}$ $0.30 \mathrm{mv}$, Johnson et al. ${ }^{13} 0.12 \mathrm{mv}$ and our data analyses showed $0.50 \mathrm{mv}$ (inspiration) and $0.30 \mathrm{mv}$ (expiration). The mean right and the mean left CMAP amplitudes were nearly identical, but there was a lack of consistent right-to-left correlation, very similar to that found by Swenson and Rubenstein ${ }^{1}$.

We found a substantial difference between genders and phrenic nerve parameters. We had significant differences in amplitude $(p=0.001)$, duration $(p=0.002)$, expiratory latency $(\mathrm{p}=0.005)$ and inspiratory amplitude $(\mathrm{p}=0.094)$. This has only previously been mentioned by Resman-Gaspersc and Podnar $^{14}$, who found a significant difference only in relation to amplitude $(p=0.03)$. It is not clear if the anthropometric variance between genders found in our study was the determinant for these substantial differences.

The correlation between phrenic nerve parameters and spirometric measures has not been reported previously. The $\mathrm{FEV}_{1}$ and FVC showed strong correlation with phrenic nerve inspiratory latencies. El-Tantawi et al. ${ }^{10}$ did not find significant correlation between spirometric parameters and phrenic nerve conduction in chronic obstructive pulmonary disease patients but they did not compare them with the data from normal individuals.

Height was strongly correlated with inspiratory latencies, as described by Resman-Gaspersc and Podnar ${ }^{14}$, and with $\mathrm{FEV}_{1}$ and FVC, as described by Knudson et al. ${ }^{16}$.

Further studies with a larger number of individuals will be needed to better understand the relationship between these spirometric parameters and inspiratory phrenic nerve CMAP latencies.

In conclusion, the normative data obtained in our participants were very similar to those available in recent articles using the same technique. In relation to the precise point of phrenic nerve stimulation in the neck, we propose that the best approach is to try both techniques, stimulating at the lateral and the medial border of the clavicular head of the sternocleidomastoid muscle in all patients and choosing the best CMAP response.

\section{References}

1. Swenson MR, Rubenstein RS. Phrenic nerve conduction studies. Muscle Nerve. 1992;15(5):597-603. https://doi.org/10.1002/mus.880150511

2. Newsom Davis J. Phrenic nerve conduction in man. J Neurol Neurosurg Psychiatry. 1967;30(5):420-6. https://doi.org/10.1136/jnnp.30.5.420

3. MacLean IC, Mattioni TA. Phrenic nerve conduction studies: a new technique and its application in quadriplegic patients. Arch Phys Med Rehabil. 1981;62(2):70-3.

4. Markand ON, Kincaid JC, Pourmand RA, Moorthy SS, King RD, Mahomed $Y$ et al. Electrophysiologic evaluation of diaphragm by transcutaneous phrenic nerve stimulation. Neurology. 1984;34(5):604-14. https://doi.org/10.1212/WNL.34.5.604

5. McKenzie DK, Gandevia SC. Phrenic nerve conduction times and twitch pressures of the human diaphragm. J Appl Physiol. 1985;58(5):1496-504.

6. Mier A, Brophy C, Moxham J, Green M. Phrenic nerve stimulation in normal subjects and in patients with diaphragmatic weakness. Thorax. 1987;42(11):885-8. https://doi.org/10.1136/thx.42.11.885

7. Chen R, Collins S, Remtulla H, Parkes A, Bolton CF. Phrenic nerve conduction study in normal subjects. Muscle Nerve. 1995;18(3):330-5. https://doi.org/10.1002/mus.880180311

8. Bolton CF, Chen R, Wijdicks EFM, Zifko UA. Neurology of breathing. Amsterdam: Elsevier; 2004.

9. Podnar S, Harlander M. Phrenic nerve conduction studies in patients with chronic obstructive pulmonary disease. Muscle Nerve. 2013;47(4):504-9. https://doi.org/10.1002/mus.23617
10. El-Tantawi GAY, Imam MH, Morsi TS. Phrenic nerve conduction abnormalities correlate with diaphragmatic descent in chronic obstructive pulmonary disease, COPD:.Journal of Chronic Obstructive Pulmonary Disease. 2015;12(5):516-24. https://doi.org/10.3109/15412555.2014.993465

11. Lu Z, Tang X, Huang X. Phrenic nerve conduction and diaphragmatic motor evoked potentials: evaluation of respiratory dysfunction. Chin Med J. 1998;111(6):496-9.

12. Hopkinson NS, Sharshar T, Ross ET, Nickol AH, Dayer MJ, Porcher R et al. Corticospinal control of respiratory muscles in chronic obstructive pulmonary disease. Respir Physiol Neurobiol. 2004;141(1):1-12. https://doi.org/10.1016/j.resp.2004.04.003

13. Johnson NE, Utz M, Patrick E, Rheinwald N, Downs M, Dilek N et al. Visualization oh the diaphragm muscle with ultrasound improves diagnostic accuracy of phrenic nerve conduction studies. Muscle Nerve. 2014;49(5):669-75. https://doi.org/10.1002/mus.24059

14. Resman-Gaspersc A, Podnar S. Phrenic nerve conductions Studies: technical aspects and normative data. Muscle Nerve. 2008;37(1):36-41. https://doi.org/10.1002/mus.20887

15. Miller MR, Hankinson J, Brusasco V, Burgos F, Casaburi R, Cates A et al. Standardization of spirometry. Eur Respir J. 2005;26(2):319-38. https://doi.org/10.1183/09031936.05.00034805

16. Knudson RJ, Lebowitz MD, Holberg CJ, Burrows B. Changes in the normal maximal expiratory flow volume curve with growth and aging. Am Rev Respir Dis. 1983;127(6):725-34. https://doi.org/10.1164/arrd.1983.127.6.725 